\title{
Power Quality Classification of disturbances using Discrete Wavelet Packet Transform (DWPT) with Adaptive Neuro-Fuzzy System
}

\author{
K.RamaMohana Reddy ${ }^{a}$ P.Ram Kishore Kumar Reddy ${ }^{b}$, P.Sujatha ${ }^{c}$ \\ ${ }^{a}$ Research Scholar, Dept.of EEE, ${ }^{b}$ Professor, Dept.of EEE, ${ }^{c}$ Professor ,Dept.of EEE \\ a,c JNTUA University,Anantapuramu., ${ }^{\mathrm{b}}$ MGIT, Hyderabad.
}

Article History: Received: 10 November 2020; Revised 12 January 2021 Accepted: 27 January 2021; Published online: 5 April 2021

\begin{abstract}
With the development of the technologies, the demand for good quality of electric power is increasing day by day. In Distributed Generation Systems (DGs), the quality of power can cause serious problems such as sensitive equipment's malfunction, the temperature riseof machines. Therefore, detection of power quality events in the power system is more important to take further actions. The existing power quality events classification methods have high computational time with low accuracy. In order to overcome this problem, this paper presents Discrete Packet Wavelet Transform-Kalman filter based Adaptive Neuro-Fuzzy approach for identification and classification of PQ events. The proposed method classifies the events with better classification accuracy, less convergence time and low in error prediction. The results show that the proposed method has better performance compared with the existing classification methods. The proposed method is Implemented and tested using MATLAB and it provides more accuracy when compared to the existing systems such as Discrete Wavelet Transform based Fuzzy Logic Adaptive System and Fourier Transform based Artificial neural networks etc.
\end{abstract}

Keywords: Adaptive Neuro-Fuzzy control, Accuracy, Convergence time, Discrete packet wavelet transform, Power quality events

\section{Introduction}

Distributed Generated System is one of the promising alternate power generation systems in today's world. Power systems like solar, wind and fuel cell come under Distributed Generated System. Widespread utilization of numerous power electronic devices from residential to commercial loads have expanded the attentionin PowerQuality (PQ) issuessuch as voltage sag/swell, flickers, harmonics etc[1]. The term PQ can be called the predetermined estimations of the electrical parameters, for example, voltage, current, and frequency [2]. In the event that these predetermined qualities deviate from some other esteem then the extreme impact will happen on the sensitive equipment. The sources of these PQ issues are not unified, for example, converters, inverters and non-linear loads [3]. Subsequently, these equipment sensitivity is expanding day-by-day. Any little change in the electric power supply will cause annoyance tripping of these equipment's [4]. As involvedin power disturbance, it is to be noticed that the exact time identification of the issue or event is vital for further change in the power quality [5]. Feature extraction can be utilized for classification utilizing Artificial Intelligent methods. Thus, there has been incredible research on the classification and representation of these PQ events [6].

Exact detection is essential and valuable for solving the issues identified with PQ issues [7]. With the methodology of signal processing in control quality applications, it is essential to develop strategies for exposing $\mathrm{PQ}$ issues for verification and examination [8].The PQ issues detection and classification are extensively known as one of the most stimulating problems in electrical engineering [9].

Initially, a recognition algorithm is utilized for detecting the disturbances form PQ issues [10]. Then, after the effective detection of disturbances, the second stage classifies them into a few groups by a machine learning strategy like Fuzzy logic [11], Support Vector Machine (SVM) [12], Artificial Neural Network (ANN) [13] and so on. It is reviewed that great highlights are fundamental for both PQ events identification and classification [14].

Feature extraction and classification of these events can be performed by Wavelet Transform (WT) [15], Fourier Transform (FT) [16], Hilbert-Huang transform [17], Kalman filter and so on. Furthermore, the features which are extracted can be utilized in pattern recognition and classification by Fuzzy, ANN and SVM and so on. Fourier Transform is time independent and gives data of frequency content available in the signal. Hence, it is unsuitable to identify the sudden variations in the PQ disturbance,like the beginning and end variation of events. Consequently, numerous researchers have proposed WT for PQ issues recognition when contrasted with FT [18] and [19]. Subsequently, there has been done tremendous research work at recognizing and classifying these unsettling influences utilizing WT. Mid-1980's WT was presented as a signal processing strategy or technique. 
Since the most recent two decades interest in applying WT to comprehend the dynamics in the power system [20] and PQ issues [6] has been expanded. The time-scale portrayal of a discrete signal is acquired utilizing digital filtering procedures in Multi-Resolution Analysis (MRA) with the addition of the Discrete Wavelet Transform (DWT).However, MRA is decomposed with the support of Low Pass and High Pass channels [21]. Short Time Fourier Transform (STFT) was utilized to detect these patterns [22]. This provides data in the time domain and frequency domain with two window capacities being utilized to get optimal resolution and increment activities. The major disadvantage of this technique is a short-settled window, so elective methodologies of wavelet change were used [23].

This paper is organized as follows. Section 2 gives the Literature review; Section 3 describes the overview of the PQ events, Section 4 explains the proposed DPWT-Kalman filter with ANFIS controller; Section 5 illustrates results and discussions followed by the conclusion in section 6 .

\section{Methodology}

The electrical signals such as voltage sag, voltage swell, flicker etc are well classified using this methodology. To improve the power quality, the detection of disturbancesin the power system is important. DWPT is a major tool for analysing power quality signals, it gives both time and frequency of the signals. The PQ Signals are given as input to DWPT. Then the PQ events such as voltage sag, voltage swell, flicker are introduced into the normal waveform. The Fault introduced to the signal is detected and classified using an adaptive neuro fuzzy algorithm.

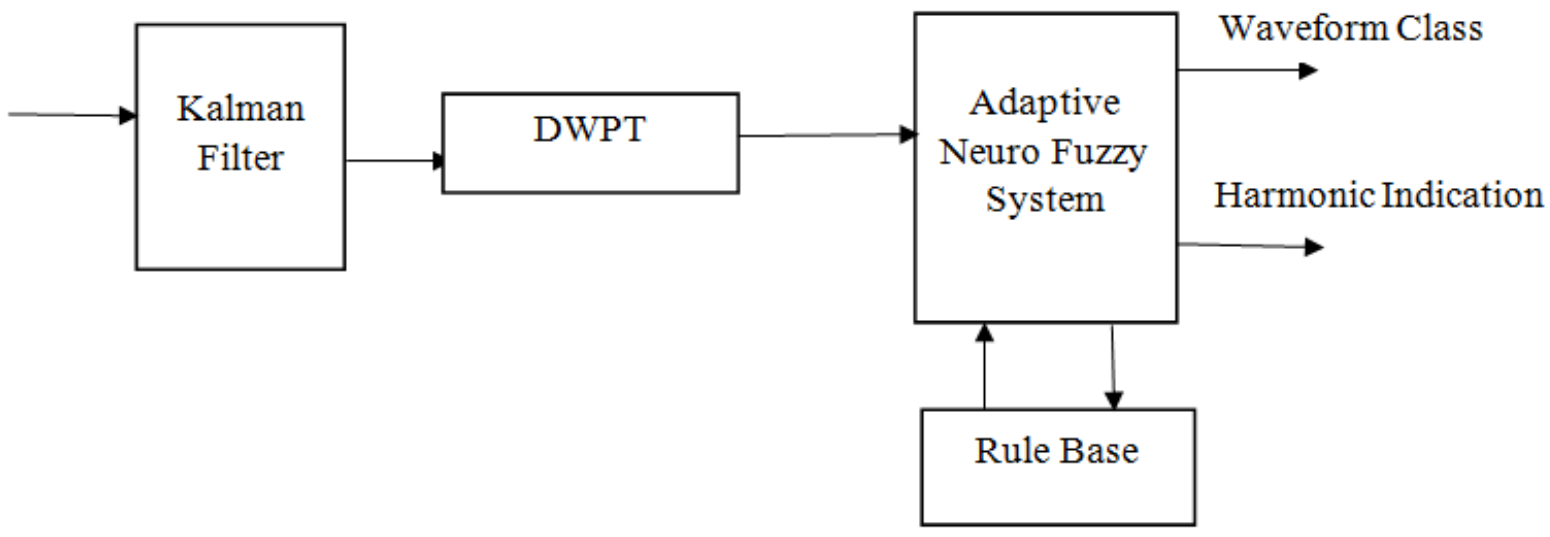

Figure1: Block Diagram of Proposed Method

\subsection{Proposed Model}

This paper presents Discrete Packet Wavelet Transform-Kalman filter based Adaptive Neuro-Fuzzy approach for identification and classification of PQ events. The events are classified by using the proposed method with better classification accuracy, less convergence time and low in error prediction. The Block diagram of the proposed system is shown in fig 1 .

\subsection{Kalman Filter}

The use of Kalman filters for protection of relays on high power systems developed in the 1980s by [37]. The Kalman filter analyses a discrete signal and filters noises. Kalman filtering performs modelling of the vector for the random process and recursive operation for the noisy measured(input) data. The Change in the magnitude of the supply voltage can be detected and analysed using Kalman Filter. The results of the Kalman Filter depend upon the system used and parameters selected for the filter. If the suitable parameters are not chosen for the Filters, then the results will be slow and diverge. The amplitudes of the fundamental frequency and harmonic components of the Voltage Waveform are used to prepare the inputs of the fuzzy-expert system.

\subsection{Power Quality Problems}

Most of the problems of customer's electrical system and equipment are due to the presence of harmonic. Another factor that can improve the quality of power is better knowledge of PQ field. The knowledge on an appropriate system for electrical wiring system is very useful to enhance the PQ. The theoretical background of the behaviour and impact of the load usage in the electrical system is important. The behaviour of load relates to the size of cable in the system, the proper mitigation technique and protective system. PQ problems are originated 
from the load. Another problem on obtaining high PQ level is the effects of natural causes such as lightning, animal and man-made problem. These types of problem cannot be avoided by the system.

\subsection{DWPT (Discrete Wavelet Packet Transform)}

The DWPT can be implemented using a multistage filter bank. The filter bank consists of wavelet function as the low-pass filters and its dual high-pass filters. An input sequence is fed into low-pass filters and its dual highpass filters, and then down sampling by a factor of two. The output from the low-pass filter provides approximation coefficients while the output from high-pass filter provides detail coefficients. Thus, at each resolution level, both the detail and approximation coefficients are decomposed by wavelet into new coefficients for the next subsequent level.

The output frequency bands of DWT do not correspond to individual harmonic components, Hence the Wavelet coefficients obtained from DWT do not provide the direct values of the harmonic amplitudes. The advancement in DWPT is that, with adequate sampling frequency and wavelet decomposition stages, it can classify the frequency bands into individual harmonic components, thereafter, harmonics amplitudes can be computed easily [38].

DWT the process of decomposing a signal into approximate Space and detail spaces of a particular wavelet. Wavelet filters can perform local analysis because the filters will have finite length, or examining a local area of a large signal. The important property of wavelet analysis is Reconstructing the decomposed signal into its original transmitted form without deterioration.

The detail space decomposition is the difference between DWT and DWPT. DWPT decomposes both the approximation Space and detail Space. In DWPT the frequency band is separated uniformly.

The Wavelets present in a Wavelet Packet are generalized in such a way that each of the octave frequency band in the wavelet spectrum is further subdivided into finer frequency bands by using the two-scale relations repeatedly. An Orthogonal basis is formed from these translates. The signal can be decomposed into many wavelet packet components. Wavelet packets provide better signal analysis than wavelet transform. The Wavelet Packet focuses on special parts of the time-frequency domain in a more detailed way than is possible with ordinary wavelet transform. The conditions to achieve a perfect reconstruction: LetG0(z) and G1(z)be the low pass analysis and synthesis filters, respectively and $\mathrm{HO}(\mathrm{z})$ and $\mathrm{H} 1(\mathrm{z})$ the high pass analysis and synthesis filters respectively. Then the filters have to satisfy the following two conditions:

$$
\begin{aligned}
& \text { G_0 (-z) G_1 (z)+H_0 (-z)H_1 (z)=0(1) } \\
& \text { G_0 (z) G_1 (z)+H_0 (z) H_1 (z) =2z-d (2) }
\end{aligned}
$$

Eqn. (1) and Eqn. (2) showsthe reconstruction and amplitude distortion of the signal.The Perfect reconstruction condition remains the same even when the analysis and Synthetic filters are switched. In this Paper DWPT (Discrete Wavelet Packet Transform) is employed with the Kalman filtered ANFIS output for generating Wavelet Packet Tree. The Wavelet Packet generated will have a particular fault that will contain nodes. Energy is calculated at each node. The net percentage of energy calculated from the nodes of the wavelet packet tree is used for classifying the power quality. A three level Wavelet Packet Tree is shown in fig 2.

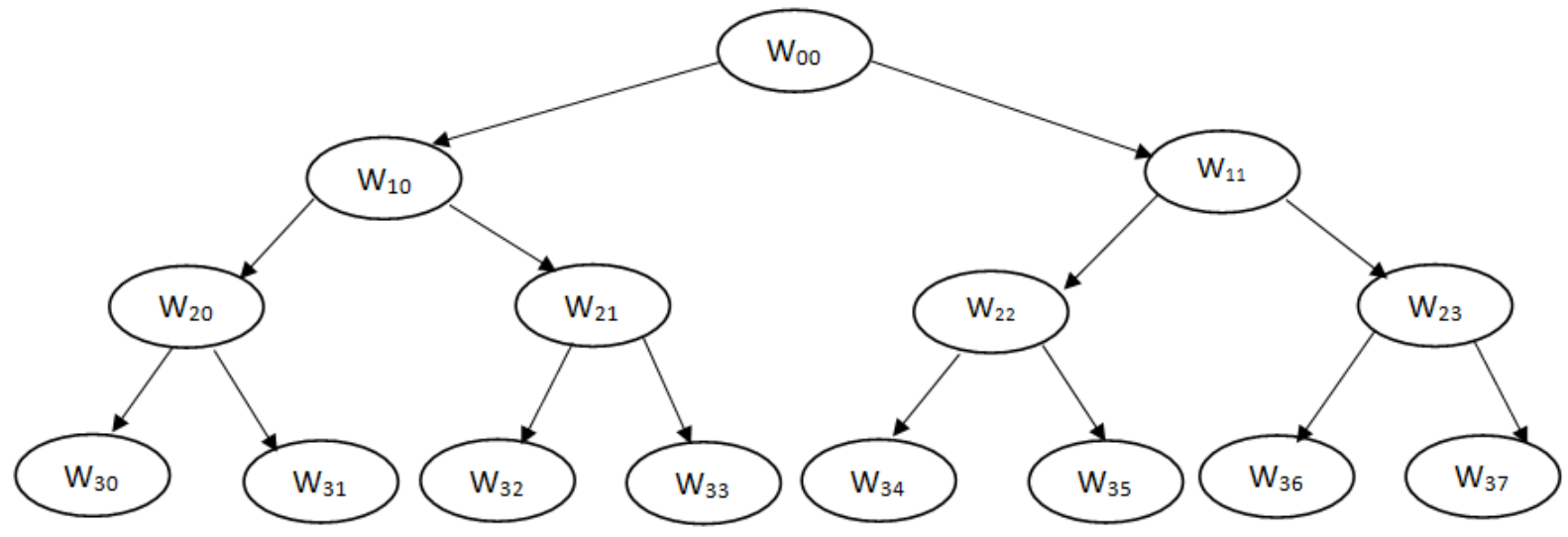

Figure 2: A three level Wavelet Packet Tree

The atoms in a Wavelet packet are Waveforms indexed by three natural parameters such as position, scale and frequency. The bases which are generated for the given Orthogonal function are called Wavelet Packet Bases. 
These bases offer a particular way of coding signals, which can be used to reconstruct the exact features. Numerous Expansions can be for a given signal using this Wavelet Packet. The most suitable decomposition of a given signal is selected by an Entropy based criteria. In the discrete wavelet transform (DWT), only the approximation part (the low-frequency part of the spectrum) is further decomposed. This chapter presents a discussion on the discrete wavelet packet transform (DWPT), where the detail part (the high-frequency part of the spectrum) is also further decomposed. The advantage of DWPT is that it is possible to select the optimal representation of the signal with respect to some criterion. The representation that uses fewer coefficients is the best in image compression. While the cost function based on a threshold is simple, more useful cost functions are based on signal energy

and other measures. The cost function which has been proposed here is Shannon entropy function. Shannon entropy function is given by

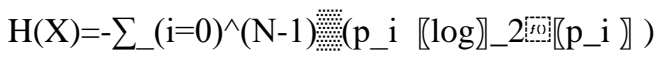

The average number of bits employed to encode a string of symbols, which depend upon the frequency of the Symbol can be determined using the equation (3). The Probability of the given signal is given by the symbolpi.

\section{ANFIS}

Adaptive-Neuro Fuzzy is employed in such a way that, the signal with the fault is sent as input (Test Data) to the trained Fuzzy Inference System. This Fuzzy Inference System is trained initially with a reference signal (Training Data) which is a signal with no fault. Energy obtained from DWPT and THD performance measure of the ANFIS output are considered for rule base of fuzzy for power quality classification for the purpose of getting better accuracy. ANFIS classifier is formed if-then rules, couples of input-output and learning algorithms of the neural network. These are used for training of ANFIS classifier [39-43].

\subsection{Structure of ANFIS:}

Parameter Identification problems are solved using ANFIS. The Parameter identification process includes a Hybrid learning rule, which is a combination of back-propagation gradient and least square method.

Generally, ANFIS is a graphical network illustration of Sugeno fuzzy systems which have the capability of neural learning. The network contains a node with specialized functions accumulated in layers. Network recognition of IF/THEN rules is possible in ANFIS[44].

For example, take the base rule ofSugeno fuzzy system

1.If $a$ is $\mathrm{X} 1$ and $b$ is $Y 1$, then $p 1=c 11 a+c 12 b+c 10$

2. If ais $\mathrm{X} 2$ and bis $\mathrm{Y} 2$, then $\mathrm{p} 2=\mathrm{c} 21 \mathrm{a}+\mathrm{c} 22 \mathrm{~b}+\mathrm{c} 20$

The membership functions of fuzzy sets $\mathrm{Xi}, \mathrm{Yi}, \mathrm{i}=1,2$, be , $\square \mathrm{Xi} \square \mathrm{Yi}$.

In the evaluation of the rules, select a product for T-norm (logical and).

1. rule properties Evaluation results in

『 $W \rrbracket \_i=\mu X \_i(a) \mu Y \_i(b), i=1,2(4)$

2. Evaluation of the implication and the rule consequences presents

$\mathrm{p}(\mathrm{a}, \mathrm{b})=\left(\mathrm{W} \_1(\mathrm{a}, \mathrm{b}) \mathrm{p} \_1(\mathrm{a}, \mathrm{b})+\mathrm{W} \_2(\mathrm{a}, \mathrm{b}) \mathrm{p} \_2(\mathrm{a}, \mathrm{b})\right) /\left(\mathrm{W} \_1(\mathrm{a}, \mathrm{b})+\mathrm{W} \_2(\mathrm{a}, \mathrm{b})\right)(5)$

On parting the arguments available are

$\mathrm{p}=\left(\mathrm{W} \_1 \mathrm{p} \_1(\mathrm{a}, \mathrm{b})+\mathrm{W} \_2 \mathrm{p} \_2\right) /\left(\mathrm{W} \_1+\mathrm{W} \_2\right)(6)$

Further it can be Divided into phases

Then pcan be written as

$\mathrm{p}=\mathrm{W} \_1 \mathrm{p} \_1+\mathrm{W} \_2 \mathrm{p} \_2(8)$

ANFIS has 5 layers of Neurons in which the Neurons of the same layer have similar functions.

$\begin{array}{lll} & \mathrm{a} & \mathrm{b} \\ \mathrm{a} & \mathrm{W} 1 \mathrm{p} 1 & \\ & \mathrm{~W} 2 \mathrm{p} 2\end{array}$


a

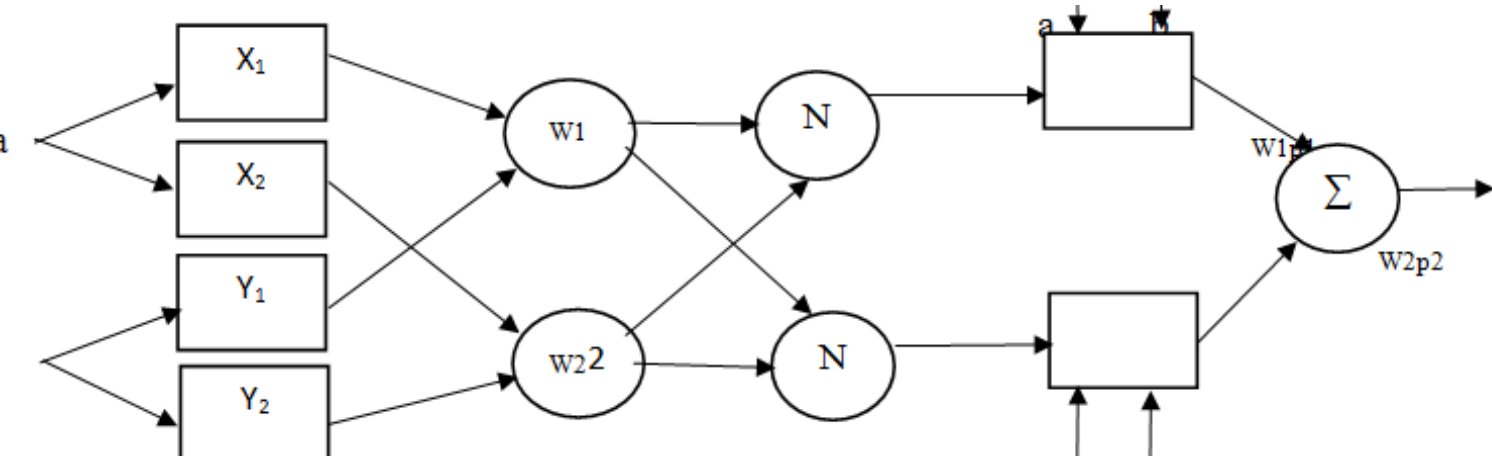

Figure 3: Structure of ANFIS

\section{L1}

L2

L3

L4

L5

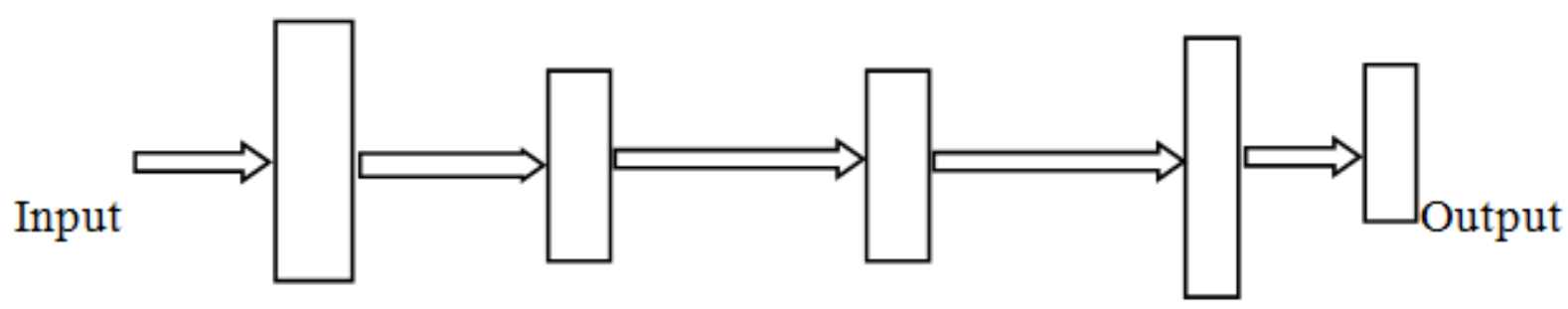

Figure 4: Architecture of ANFIS

Layer 1 (L1): Every node creates the membership ratings of a linguistic label.

A sample of a membership function is the general bell function:

(9)

Where,

$\{a, b, c\}-$ parameter set.

The Parameters in the Layer are called as premise parameters as the parameter varies the shape of the bellshaped function changes.

Layer 2 (L2): Rules firing strength of each node is computed. Generally, any other fuzzy AND operation can be utilized.

Layer 3 (L3): The ratio of rule's firing strength to the amount of all rules firing strength is computed is computed as normalised firing strength.

Layer 4 (L4): A parameter function is calculated at the output of layer 3. These parameters are called consequent parameters.

Layer 5 (L5): The Final Layer, a single node Collects the overall output as the aggregation of all incoming signals.

Once the fuzzy-expert system is designed, the classification of different disturbances can then be made. To test the accuracy of the proposed fuzzy-expert system, distorted voltage waveforms are generated, and this has a different time of occurrence, duration, and amplitude. After calculating the energy on each wavelet decomposition level, the feature extraction curve is obtained; and then the classification of each waveform into a different category by using the fuzzy-expert system is performed.The Wavelet packet transform is used to decompose and reconstruct the signals. The fuzzy-expert system is efficient for power quality disturbance classification. Although only five types of the waveform are classified, it is possible to classify even more than five types. To classify the new type of power quality disturbance new rule base is developed based on the feature extraction curve of the new disturbances.

Fuzzy logic allows the user to assign weighting factors for defined states, or membership in a set. The degrees of membership assigned to variables provides for dealing with uncertainty and ambiguity that is not 
possible in simple Boolean logic. Knowledge about a system can be described in terms of rules and membership functions. As the number of rules grows, the system response time slows down. It also takes time to refine the rules and membership values. The accuracy of the system is based on the knowledge of human experts; hence, it is only as good as the validity of the rules.

The Faultless signal is used as train data for ANFIS, when a fault signal like Voltage sag, Voltage Swell, Flicker and Harmonics are passed as test data it detects the type of fault occurred and displays in the M classification output. This paper presents Discrete Packet Wavelet Transform-Kalman filter based Adaptive Neuro-Fuzzy approach for identification and classification of PQ events. The events are classified by using the proposed method with better classification accuracy, less convergence time and low in error prediction.

\section{SIMULATION RESULTS}

The tested signals of power quality are voltage sag, voltage swell, flicker and harmonics. These signals aresimulated using MATLAB and are shownFigs 6, 9,12,15,18.

\section{No Fault condition}

Under this condition the signal without any fault is passed through the system.

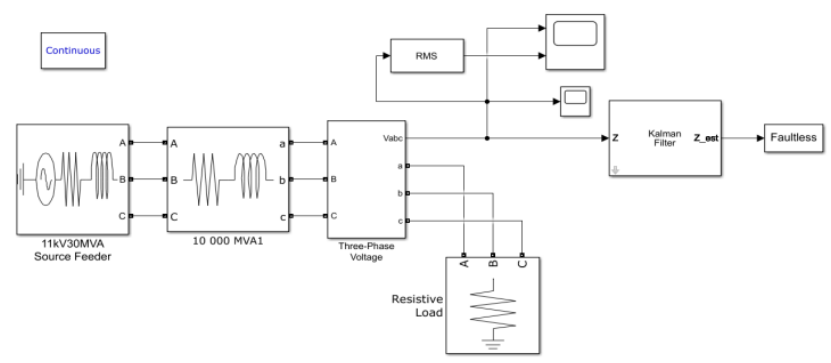

Figure 5: Simulink Block diagram of a faultless condition

The Faultless 3 phase signal representation is shown in fig 7. No fault is introduced to the system hence the classification output is no fault found

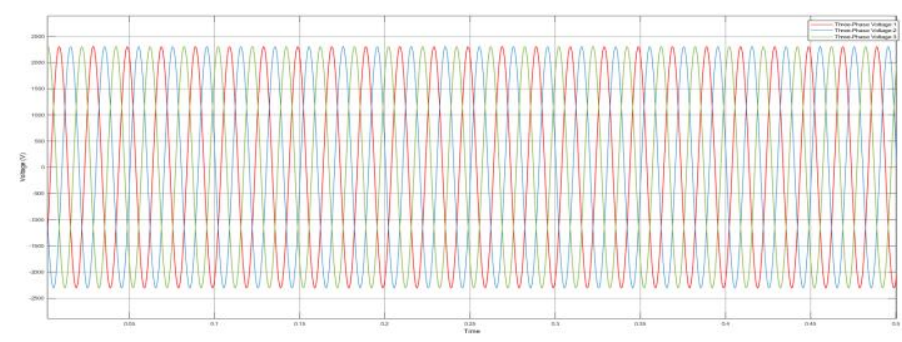

Figure 6:Faultless 3 phase signal

AS no fault has been introduced a Normally distributed 3 phase signal is shown in fig 6. Wavelet transform analysis is carried out with the faultless signal and is passed through the ANFIS model. Since the signal is faultless the M-file classification output shown is no fault as shown in fig7.

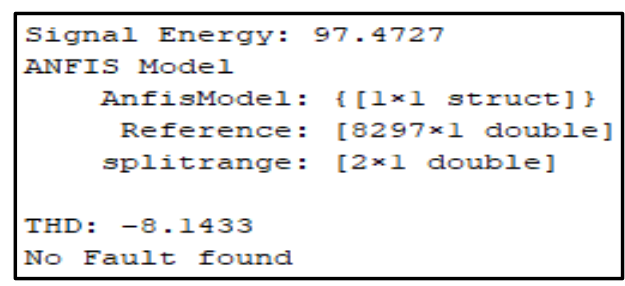

Figure 7: M-file Classification output

\section{Voltage Sag}

Voltage sags are a Common occurring phenomenon in supply systems. For generation of sag voltage in MATLAB simulation model, we consider $11 \mathrm{KV}$ transmission model with 440 Volt, 50Hz Resistive Load. Sag generated in between 1 to 1.5 second. 


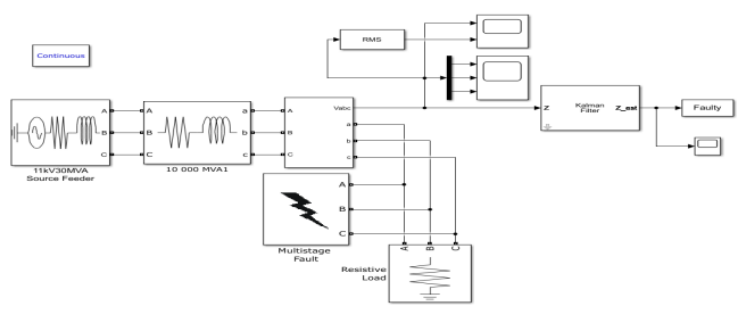

Figure 8: Simulink Block diagram for Voltage Sag fault condition

Wavelet transform analysis has been carried out on sag waveform. The five level decomposition gives five Energy coefficients. The detail coefficients are different for each and every power quality disturbance. The 3 phase signal for voltage sag fault condition is shown in fig 9.

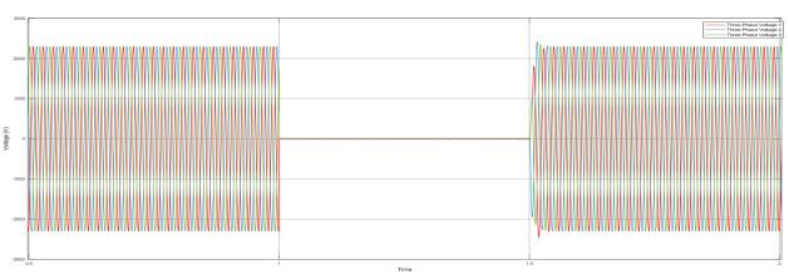

Figure 9:3 phase signal for Voltage Sag fault condition

Faultless signal is used as train data. When a Fault signal is passed through ANFIS as test data, it identifies the Fault through ANFIS model and detect the type of fault. Here the Fault is identified as Voltage sag and is displayed in a M-file classification output as shown in fig 10.

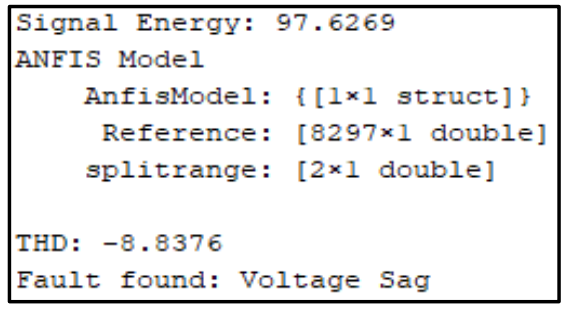

Figure 10: M-file Classification output

\section{Voltage Swell}

For generation of swell voltage in MATLAB simulation model, we consider $11 \mathrm{KV}$ transmission model with 440 Volt, 50Hz Resistive load of 30 KVAR. Swell generated in between 2 to 2.5 second.

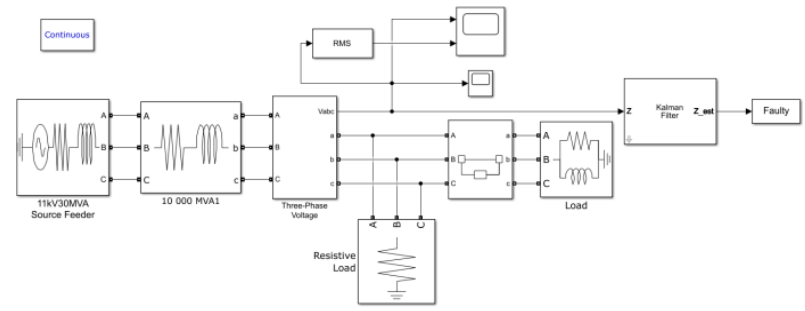

Figure 11: Simulink Block diagram for Voltage Swell fault condition

Wavelet transform analysis has been carried out on swell waveform. The output of the 3 phase signal for voltage swell fault condition is shown in fig 12.

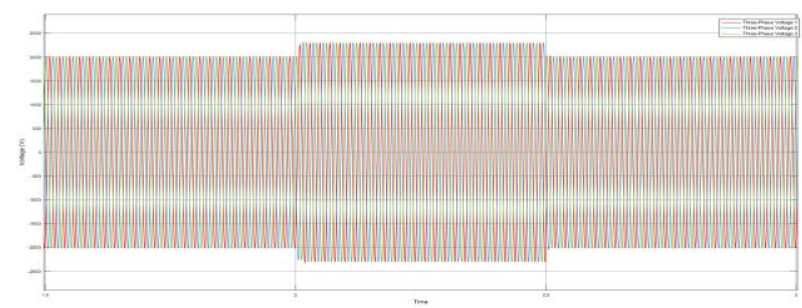

Figure 12: 3 phase signal for Voltage Swell fault condition 
Faultless signal is used as train data. When a Fault signal is passed through ANFIS as test data, it identifies the Fault through ANFIS model and detect the type of fault. Here the Fault is identified as Voltage swell and is displayed in a M-file classification output as shown in fig 13.

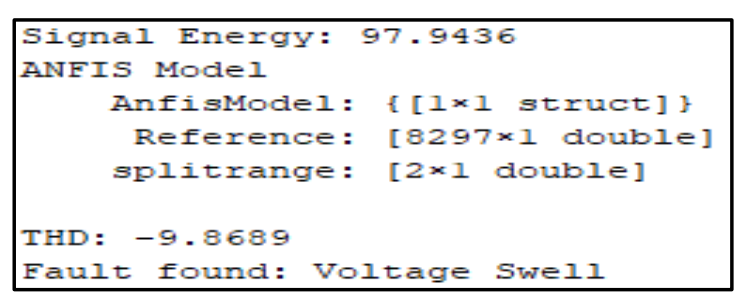

Figure 13: M-file Classification output

\section{Flicker}

Flicker noise is characterized by a power spectral density that is inversely proportional to the frequency. The results in fig 15 shows the flicker's energy deviation levels. Voltage flicker or flickering can be characterized as cyclic variations in magnitude of voltage. Electrical devices are not harmed by voltage variances, but rather these fluctuations may bring about adjustment in brightening intensity of light devices. Voltage flicker may result in unpleasant visual sensation, which becomes the source of complaints from utility customers. The disturbance level and unpleasant visual sensation depends on the type of lamp and characteristics (amplitude, frequency and duration) of the flickering.

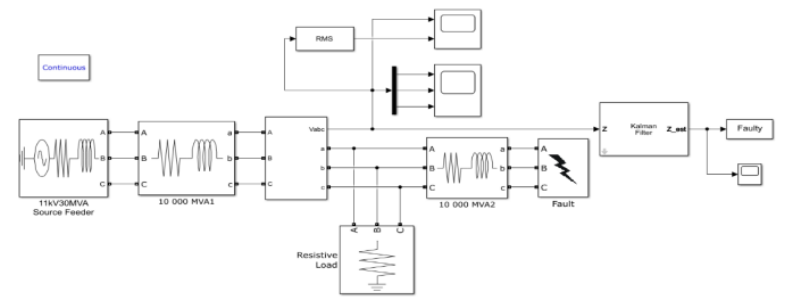

Figure 14: Simulink Block diagram for Flicker fault condition

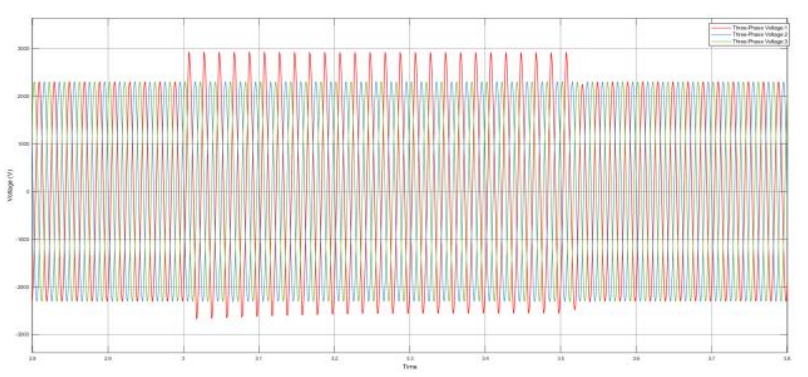

Figure 15: 3 phase signal for Flicker fault condition

Flicker occurred at time $1=3$ to 3.5 is shown in fig15. The Flicker detected is Shown in M-file classification output.

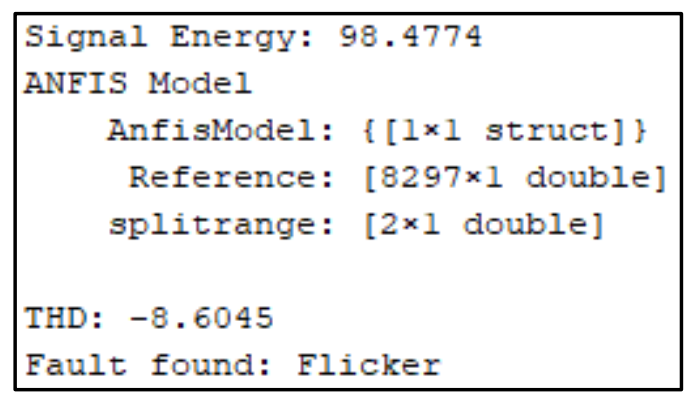

Figure 16: M-file Classification output

\section{Harmonics}

Harmonics are created in an electric power system as the result of nearby nonlinear loads. Consonant voltages and current in the power matrix framework are one of the successive explanations behind power quality issues. 


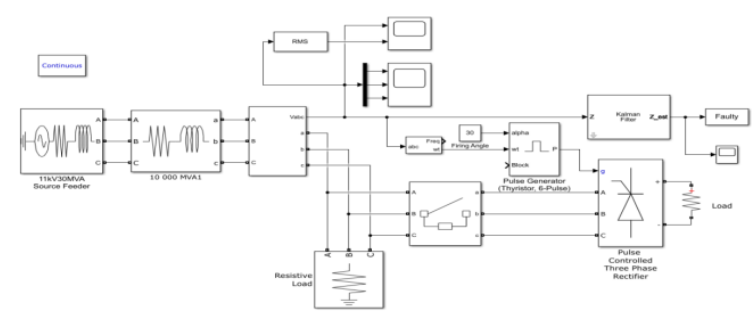

Figure 17: Simulink Block diagram for Harmonics fault condition

The Output of 3 phase signal for the harmonic fault condition is shown in figure 18.

The signal is passed into the ANFIS classifier; the disturbance occurred is identified as

Harmonics and is shown in the M-file Classification output as shown in fig 19.

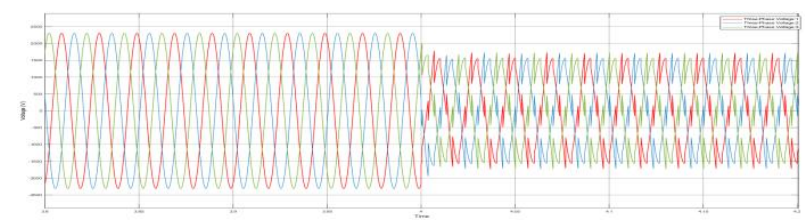

Figure 18: 3 phase signal for Harmonics fault condition

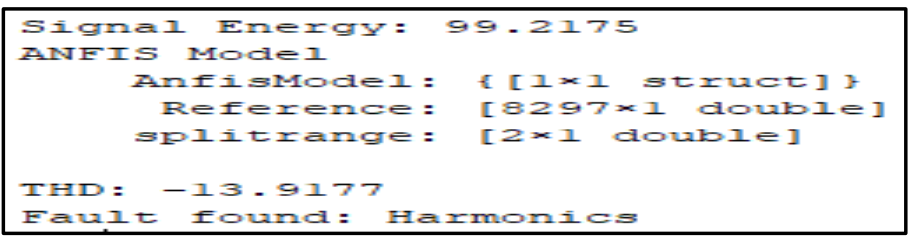

Figure 19: M- File Classification output

The Proposed method is found to be better When Compared to the Existing methods. Comparative Analysis is shown in Table1, the proposed method is compared with the previous existing methods and the accuracy of the proposed method is found better.

Table 1: Comparative Analysis

\begin{tabular}{|l|l|l|}
\hline 1 & $\begin{array}{l}\text { DWPT with adaptive } \\
\text { Neuro Fuzzy System using } \\
\text { Kalman Filter }\end{array}$ & $\mathbf{9 8 \%}$ \\
\hline 2 & $\begin{array}{l}\text { Hybrid Method based on S- } \\
\text { Transform and Dynamics/ } \\
\text { Decision Tree[45]. }\end{array}$ & $97.9 \%$ \\
\hline 3 & $\begin{array}{l}\text { High-Order Statistic/Neuro- } \\
\text { Tree[46] }\end{array}$ & $97.8 \%$ \\
\hline 4 & $\begin{array}{l}\text { Dictionary Learning Sparse } \\
\text { Decomposition/Decision } \\
\text { Tree[47] }\end{array}$ & $97.5 \%$ \\
\hline
\end{tabular}

\section{Conclusions}

This paper presented a unique method for classification of power quality disturbances based on discrete wavelet packet transform with adaptive neuro fuzzy system. High classification accuracy rate of $98 \%$ was achieved by this proposed method with the use of discrete wavelet packet transform. The proposed method has better performance and accuracy when compared with the existing classification methods.. 


\section{References}

Nazerian, E., Gharebaghi, S., \&Safdarian, A. (2017, December). Optimal distribution network reconfiguration considering power quality issues. In Smart Grid Conference (SGC), 2017 (pp. 1-6). IEEE.

Patel, A., Mathur, H. D., \&Bhanot, S. (2018). An improved control method for unified power quality conditioner with an unbalanced load.International Journal of Electrical Power \& Energy Systems, 100, 129-138.

Elbasuony, G. S., Aleem, S. H. A., Ibrahim, A. M., \&Sharaf, A. M. (2018). A unified index for power quality evaluation in distributed generation systems. Energy, 149, 607-622.

Montoya, F., Baños, R., Alcayde, A., Montoya, M., \&Manzano-Agugliaro, F. (2018). Power Quality: Scientific Collaboration Networks and Research Trends. Energies, 11(8), 2067.

Thirumala, K., Jain, T., \&Umarikar, A. C. (2017). Visualizing time-varying power quality indices using generalized empirical wavelet transform. Electric power systems research, 143, 99-109.

Achlerkar, P. D., Samantaray, S. R., \&Manikandan, M. S. (2018). Variational mode decomposition and decision tree based detection and classification of power quality disturbances in grid-connected distributed generation system. IEEE Transactions on Smart Grid, 9(4), 3122-3132.

Saini, M. K., \&Beniwal, R. K. (2017). Optimum fractionally delayed wavelet design for PQ event detection and classification. International Transactions on Electrical Energy Systems, 27(10), e2408.

Kumawat, P., Zaveri, N., \&Verma, D. (2017, July). Analysis of power quality disturbances using M-band wavelet packet transform. In Signal Processing and Communication (ICSPC), 2017 International Conference on (pp. 364-368). IEEE.

Shitole, A. B., Suryawanshi, H. M., Talapur, G. G., \&Sathyan, S. (2017, June). Performance improvement of grid interfaced three level diode clamped inverter under various power quality events. In 2017 IEEE 26th International Symposium on Industrial Electronics (ISIE) (pp. 821-826).IEEE.

Oubrahim, Z., Choqueuse, V., Amirat, Y., \&Benbouzid, M. E. H. (2017). Disturbances classification based on a model order selection method for power quality monitoring IEEE Transactions on Industrial Electronics, 64(12), 9421-9432.

Mahela, O. P., \&Shaik, A. G. (2017). Power quality recognition in distribution system with solar energy penetration using S-transform and Fuzzy C-means clustering. Renewable energy, 106, 37-51.

HAJIBANDEH, N., Faghihi, F., Ranjbar, H., \&Kazari, H. (2017). Classifications of disturbances using wavelet transform and support vector machine. Turkish Journal of Electrical Engineering \& Computer Sciences, $25(2), 832-843$.

Ma, J., Zhang, J., Xiao, L., Chen, K., \& Wu, J. (2017). Classification of power quality disturbances via deep learning. IETE Technical Review, 34(4), 408-415.

Hafiz, F., Swain, A., Naik, C., \& Patel, N. (2017, November). Feature selection for power quality event identification. In Region 10 Conference, TENCON 2017-2017 IEEE (pp. 2984-2989).IEEE.

Wang, Y., Kong, Y., Ravishankar, J., Phung, T., \& Le, P. N. (2018, April). ANALYSIS AND DETECTION OF TRANSIENTS IN ISLANDED MICRO-GRIDS USING WAVELET TRANSFORMATION. In 2018 th International Conference on Electric Power and Energy Conversion Systems (EPECS) (pp. 1-6).IEEE.

Alqam, S. J., \&Zaro, F. R. (2018). Power Quality Detection and Classification Using S-Transform and RuleBased Decision Tree.

Sundaram, P. K., \&Neela, R. (2017, May). Analysis and classification of power quality events using Hilbert transform and fuzzy system. In Sensing, Signal Processing and Security (ICSSS), 2017 Third International Conference on (pp. 269-274). IEEE.

Andrade, L. C., Oleskovicz, M., \&Fernandes, R. A. (2016). Adaptive threshold based on wavelet transform applied to the segmentation of single and combined power quality disturbances. Applied Soft Computing, 38, 967-977.

Sahani, M., \& Dash, P. K. (2018). Automatic Power Quality Events Recognition Based on Hilbert Huang Transform and Weighted Bidirectional Extreme Learning Machine. IEEE Transactions on Industrial Informatics, 14(9), 3849-3858.

Jaiswal, S., \&Ballal, M. S. (2017). FDST-based PQ event detection and energy metering implementation on FPGA-in-the-loop and NI-LabVIEW. IET Science, Measurement \& Technology, 11(4), 453-463.

Nguyen, B. N., Quyen, A. H., Nguyen, P. H., \& Ton, T. N. (2017, July). Wavelet-based Neural Network for recognition of faults at NHABE power substation of the Vietnam power system. In System Science and Engineering (ICSSE), 2017 International Conference on (pp. 165-168). IEEE.

Okelola, M. O. (2018). Power Quality Events Classification on Real-Time Voltage Waveform Using Short Time Fourier Transform and Bayes Classifier. International Journal of Applied, 8(2).

Vo, B., Le, T., Pedrycz, W., Nguyen, G., \&Baik, S. W. (2017). Mining erasable itemsets with subset and superset itemset constraints. Expert Systems with Applications, 69, 50-61. 
Khokhar, S., Zin, A. A. M., Memon, A. P., \&Mokhtar, A. S. (2017). A new optimal feature selection algorithm for classification of power quality disturbances using discrete wavelet transform and probabilistic neural network. Measurement, 95, 246-259.

Singh, U., \& Singh, S. N. (2017). Application of fractional Fourier transform for classification of power quality disturbances. IET Science, Measurement \& Technology, 11(1), 67-76.

Borrás, M. D., Bravo, J. C., \&Montaño, J. C. (2016). Disturbance ratio for optimal multi-event classification in power distribution networks. IEEE Transactions on Industrial Electronics, 63(5), 3117-3124.

Rodriguez-Guerrero, M. A., Jaen-Cuellar, A. Y., Carranza-Lopez-Padilla, R. D., Osornio-Rios, R. A., HerreraRuiz, G., \& Romero-Troncoso, R. D. J. (2018). Hybrid Approach Based on GA and PSO for Parameter Estimation of a Full Power Quality Disturbance Parameterized Model. IEEE Transactions on Industrial Informatics, 14(3), 1016-1028.

Alkhraijah, M. M., \&Abido, M. A. (2017, May). Power Quality Classification Using Neuro-Fuzzy Logic Inference System. In 2017 9th IEEE-GCC Conference and Exhibition (GCCCE) (pp. 1-4). IEEE.

Babu, N. R., \& Mohan, B. J. (2017). Fault classification in power systems using EMD and SVM. Ain Shams Engineering Journal, 8(2), 103-111.

Chang, P. C., Chang, G. W., Shih, M. H., Chen, Y. Y., Hong, Y. H., \&Yeh, Y. K. (2017, July). A hybrid approach for detection and classification of power quality disturbances. In Power \& Energy Society General Meeting, 2017 IEEE (pp. 1-5). IEEE.

Kamthekar, P. R., Gautam, P. V., \&Munje, R. K. (2017, February). Detection, characterization, and classification of short duration voltage events using DWT and fuzzy logic.In Innovative Mechanisms for Industry Applications (ICIMIA), 2017 International Conference on (pp. 242-247).IEEE.

Kamthekar, P. R., Munje, R. K., \&Kushare, B. E. (2017, February). Detection and classification of power quality events using DWT and MSD.In Innovative Mechanisms for Industry Applications (ICIMIA), 2017 International Conference on (pp. 150-157).IEEE.

Huang, J., Jiang, Z., Rylands, L., \&Negnevitsky, M. (2017). SVM-based PQ disturbance recognition system. IET Generation, Transmission \& Distribution, 12(2), 328-334.

Markovska, M., \&Taskovski, D. (2017, July). Optimal wavelet-based feature extraction and classification of power quality disturbances using random forest.In Smart Technologies, IEEE EUROCON 2017-17th International Conference on (pp. 855-859).IEEE.

Chakraborty, A., \&Mandal, R. (2017, August). A novel technique employing DWT-based envelope analysis for detection of power system transients.In 2017 International Conference on Energy, Communication, Data Analytics and Soft Computing (ICECDS) (pp. 346-350).IEEE.

Urbina-Salas, I., Razo-Hernandez, J. R., Granados-Lieberman, D., Valtierra-Rodriguez, M., \& Torres-Fernandez, J. E. (2017). Instantaneous Power Quality Indices Based on Single-Sideband Modulation and Wavelet Packet-Hilbert Transform. IEEE Transactions on Instrumentation and Measurement, 66(5), 1021-1031.

J. Barros and R. Diego, "Analysis of Harmonics in Power Systems Using the Wavelet-Packet Transform," IEEE Trans. Instrum. Meas., vol. 57, no. 1, pp. 63-69, Jan 2008.

Girgis AA. A new Kalman filtering based digital distance relay. IEEE Trans Power ApparSyst 1982;PER2(9):65-6.A. (1982).Girgis AA. A new Kalman filtering based digital distance relay. IEEE Transactions on Power Apparatus and Systems, (9), 3471-3480.

Kosko, B. (1992). Neural networks and fuzzy systems: a dynamical systems approach to machine intelligence/book and disk. Vol. 1Prentice hall.

Jang, J. S., \& Sun, C. T. (1995). Neuro-fuzzy modeling and control. Proceedings of the IEEE, 83(3), 378-406.

Jang, J. S. (1993). ANFIS: adaptive-network-based fuzzy inference system. IEEE transactions on systems, man, and cybernetics, 23(3), 665-685.

Avci, E., Turkoglu, I., \&Poyraz, M. (2005, June). Intelligent target recognition based on wavelet adaptive network based fuzzy inference system. In Iberian Conference on Pattern Recognition and Image Analysis (pp. 594-603).Springer, Berlin, Heidelberg.

Çomak, E., Arslan, A., \&Türkoğlu, İ. (2007). A decision support system based on support vector machines for diagnosis of the heart valve diseases. Computers in biology and Medicine, 37(1), 21-27.

Güler, I., \&Übeyli, E. D. (2005). Adaptive neuro-fuzzy inference system for classification of EEG signals using wavelet coefficients. Journal of neuroscience methods, 148(2), 113-121.

He, S., Li, K., \& Zhang, M. (2013). A real-time power quality disturbances classification using hybrid method based on S-transform and dynamics. IEEE transactions on instrumentation and measurement, 62(9), 24652475.

Ribeiro, E. G., Mendes, T. M., Dias, G. L., Faria, E. R., Viana, F. M., Barbosa, B. H., \& Ferreira, D. D. (2018). Real-time system for automatic detection and classification of single and multiple power quality disturbances. Measurement, 128, 276-283.

Cai, D., Li, K., He, S., Li, Y., \&Luo, Y. (2018). A highly accurate and fast power quality disturbances classification based on dictionary learning sparse decomposition. Transactions of the Institute of Measurement and Control. 
